www.jmscr.igmpublication.org

Impact Factor (SJIF): 6.379

Index Copernicus Value: 79.54

ISSN (e)-2347-176x ISSN (p) 2455-0450

crossrefDOI: https://dx.doi.org/10.18535/jmscr/v6i10.118

Journal Of Medical Science And Clinical Research

IGM Publication

An Official Publication of IGM Publication

\title{
A Study on Atopy, Contact Sensitization and Hand Eczema
}

Authors

\section{Yasmine Ibrahim $^{1}$, Reena Chandran ${ }^{2}$, Anuja Elizabeth George ${ }^{3}$}

${ }^{1}$ Senior Resident, Department of Dermatology \& Venereology, Govt. Medical College, Kollam

${ }^{2}$ Assistant Professor, Department of Dermatology \& Venereology, Govt. Medical College,

Thiruvananthapuram

${ }^{3}$ Professor \& Head of the Department, Department of Dermatology \& Venereology, Govt. Medical College,

Thiruvananthapuram, India

*Corresponding Author

\section{Reena Chandran}

Email: reenachandranderma75@gmail.com

\begin{abstract}
Background: Atopic dermatitis and hand eczema are common chronic and relapsing inflammatory skin conditions that often co-occur. Many factors like age of onset, personal and family history of atopy and severity atopic dermatitis influence the risk of developing hand eczema.

Aims: To find out the proportion of patch test positivity in atopic individuals with hand eczema and to identify the specific contact allergens in these patients.

Materials \& Methods: This was a cross-sectional study involving 56 hand eczema patients conducted between January 2016 and December 2016, at a tertiary care centre in Southern India. After a detailed history and detailed examination, patch test was done on all the patients with hand eczema using the Indian standard series. The readings were interpreted according to International Contact Dermatitis Research Group criteria and noted down. The data collected were analysed in terms of descriptive statistics. The test of association was done using Chi-square test.

Results: A total of 56 patients with hand eczema were studied. Among the 56 patients, 34 participants (60.7\%) had positive patch test reaction. 24 patients in the study group had atopy, among whom $70.8 \%$ had a positive patch test reaction. Most common allergen yielding positive results were Potassium dichromate (20.8\%), Nickel sulphate (17\%) and Thiuram mix (15.1\%). Patients with atopic dermatitis were more frequently sensitive to Thiuram mix than non atopics. Most of the patients had a non-specific morphological pattern of hand eczema (66.1\%) followed by wear and tear dermatitis. A similar pattern was seen in atopic individuals also. No statistical association could be found out between pompholyx and atopy $(p=0.659)$.

Conclusions: Patients with atopic dermatitis should be patch tested when indicated because they also develop contact allergic sensitization to a significant degree. Our observations indicate that patch testing with standard allergens often add valuable information about contact sensitivity in these patients. Clinicians should guide patients with atopic dermatitis away from occupation with a high risk of hand eczema. A specific morphology for hand eczema is not seen in most of the times. There was no increase risk for the development of pompholyx in atopic patients.

Keywords: hand eczema, contact dermatitis, patch test.
\end{abstract}




\section{Introduction}

Hand eczema is a type of endogenous eczema in which the dermatoses is largely confined to the hands, with only minor involvement of other areas. ${ }^{1}$ It is a common distressing condition giving rise to a lot of emotional and physical morbidity. ${ }^{2}$ Various exogenous and endogenous factors are implicated in the development of hand eczema. Different morphological types of hand eczema have been described. ${ }^{1}$ Individuals with atopic dermatitis developed more severe hand eczema. Also atopic dermatitis was found to increase the odds of developing hand eczema by three times in wet as well as in dry work ${ }^{3}$. They also seem to have a considerable risk of developing hand eczema when exposed to occupational agents ${ }^{4}$. Among the exogenous factors, frequency of hand eczema seemed to be higher at exposure to some chemicals like detergents than to others like solvents ${ }^{5}$.

Avoidance of the allergen and maintanence of the cutaneous barrier is important in the prevention of recurrences in hand eczema.

\section{Materials and Methods}

This was a cross-sectional study conducted between January 2016 and December 2016, at a tertiary care centre in Southern India. The study was done after obtaining approval from the institutional ethics committee. Consecutive patients above the age of 12 years with hand eczema attending the Department of Dermatology, Venereology and Leprosy, who had given consent to participate in the study, were included in the study. Patients who had received oral steroids in the past 2 weeks and patients who were pregnant or lactating were excluded from the study.

\section{Procedure}

After informed consent, detailed history including history of occupational/personal exposure to chemicals, history of atopy and detailed examination findings with area of involvement, morphology and final diagnosis were noted down in the proforma. Patch testing was done in all patients with Indian standard series, approved by
Contact and Occupational Dermatoses Forum of India (CODFI) marketed by Systopic Laboratories Pvt. Ltd., New Delhi with 20 allergens. The patches were removed after 48 hours. The reading was taken one hour after removal of the patches, to allow the erythema to subside. A second reading was taken after 96 hours. The readings were interpreted according to International Contact Dermatitis Research Group criteria.

The data collected were analysed using descriptive statistics. The test of association was done with Chi-square test.

\section{Results}

There was a slight male preponderance with the male to female ratio $1.07: 1$. The mean age of the patients was 40.6 years and maximum patients were in the age group 35-44 years (35.7\%). Out of the 56 participants, 16 of them were housewives (28.6\%), followed by 13 masons (23.2\%) (Table 1).

Table 1 Occupation

\begin{tabular}{|l|c|c|}
\hline Occupation & Frequency & Percent \\
\hline Mason & 13 & 23.2 \\
\hline Housewife & 16 & 28.6 \\
\hline Nursing assistant & 7 & 12.5 \\
\hline Painting & 2 & 3.6 \\
\hline Office work & 3 & 5.4 \\
\hline Student & 4 & 7.1 \\
\hline Farmer & 4 & 7.1 \\
\hline Nurse & 1 & 1.8 \\
\hline Miscellaneous & 4 & 7.1 \\
\hline Tile worker & 1 & 1.8 \\
\hline Cattle rearing & 1 & 1.8 \\
\hline Total & 56 & 100.0 \\
\hline
\end{tabular}

The patients were classified into two groups: group I atopic patients (24 patients) and group II non atopic patients (32 patients). Multiple sensitivities were observed and the clinical relevance of positive reactions were determined.

Table 2 Positive patch test reactions in atopics and non atopics

\begin{tabular}{|l|c|c|c|}
\hline & $\begin{array}{c}\text { Tested } \\
\text { patients }\end{array}$ & $\begin{array}{c}\text { Positive } \\
\text { reactions }\end{array}$ & $\begin{array}{c}\text { Percentage per } \\
\text { positive reactors }\end{array}$ \\
\hline $\begin{array}{l}\text { Atopic } \\
\text { patients }\end{array}$ & 24 & 17 & $50 \%$ \\
\hline $\begin{array}{l}\text { Non atopic } \\
\text { patients }\end{array}$ & 32 & 17 & $50 \%$ \\
\hline Total & 56 & 34 & $100 \%$ \\
\hline
\end{tabular}


Table 3 Pattern of hand eczema in atopics

\begin{tabular}{|l|c|c|}
\hline Pattern & Frequency & $\begin{array}{c}\text { Percentage } \\
(\mathbf{\%})\end{array}$ \\
\hline Pompholyx & 4 & 16.7 \\
\hline Fingertip eczema & 1 & 4.2 \\
\hline $\begin{array}{l}\text { Wear and tear } \\
\text { dermatitis }\end{array}$ & 5 & 20.8 \\
\hline Unspecified & 14 & 58.3 \\
\hline Total & 24 & 100 \\
\hline
\end{tabular}

Females showed a predominance in the atopic group (54.2\%). $20.8 \%$ of the patients had wear and tear dermatitis, $16.7 \%$ had pompholyx, $4.2 \%$ had fingertip eczema and $58.3 \%$ of patients could not be classified into any specific category (Table $3)$.

Out of the 8 patients who had pompholyx, 4 had a history of atopy while the rest four had no history of atopy. A significant association between the two could not be obtained ( $\mathrm{p}=0.659)$ (Table 4).

Table 4 Pompholyx with Personal history of atopy

\begin{tabular}{|c|c|c|c|c|c|c|}
\hline \multirow{3}{*}{ Pompholyx } & \multicolumn{4}{|c|}{ Personal history of atopy } & \multirow{2}{*}{\multicolumn{2}{|c|}{ Total }} \\
\hline & \multicolumn{2}{|c|}{ Yes } & \multicolumn{2}{|c|}{ No } & & \\
\hline & $\mathrm{N}$ & $\%$ & $\mathrm{~N}$ & $\%$ & $\mathrm{~N}$ & $\%$ \\
\hline Yes & 4 & 16.7 & 4 & 12.5 & 8 & 14.3 \\
\hline No & 20 & 83.3 & 28 & 87.5 & 48 & 85.7 \\
\hline Total & 24 & 100.0 & 32 & 100.0 & 56 & 100.0 \\
\hline
\end{tabular}

$\mathrm{N}=$ number of patients

In group I, 17 patients $(70.8 \%)$ had a positive patch test. Thiuram mix was the most common allergen identified in $6(22.3 \%)$, followed by potassium dichromate in $5(18.5 \%)$ and nickel sulphate in 4 (14.8\%) (Table 5).

Table 5 Allergens positive in patch test in group I (atopics)

\begin{tabular}{|l|c|c|}
\hline Allergens & Frequency & $\begin{array}{c}\text { Percentage } \\
(\mathbf{\%})\end{array}$ \\
\hline Formaldehyde & 2 & 7.4 \\
\hline Mercaptobenzthiazole & 2 & 7.4 \\
\hline Potassium dichromate & 5 & 18.5 \\
\hline Nickel sulphate & 4 & 14.8 \\
\hline Cobalt sulphate & 3 & 11.1 \\
\hline Paraphenylenediamine & 1 & 3.7 \\
\hline Parthenium & 2 & 7.4 \\
\hline Neomycin sulphate & 1 & 3.7 \\
\hline Fragrance mix & 1 & 3.7 \\
\hline Thiuram mix & 6 & 22.3 \\
\hline
\end{tabular}

Patch test positive to two or more allergens was seen 8 out of 24 patients (33.3\%)

In group II, 17 patients $(53.1 \%$ ) had a positive patch test. Potassium dichromate was the most common allergen $(23.1 \%)$, followed by nickel sulphate (19.3\%) and fragrance mix (15.5\%) (Table 6).

Table 6 Allergens positive in patch test in group II (non atopics)

\begin{tabular}{|l|c|c|}
\hline Allergens & Frequency & $\begin{array}{c}\text { Percentage } \\
(\mathbf{\%})\end{array}$ \\
\hline Balsum of Peru & 1 & 3.8 \\
\hline Formaldehyde & 1 & 3.8 \\
\hline Mercaptobenzthiazole & 1 & 3.8 \\
\hline Potassium dichromate & 6 & 23.1 \\
\hline Nickel sulphate & 5 & 19.3 \\
\hline Cobalt sulphate & 2 & 7.7 \\
\hline Epoxy resins & 2 & 7.7 \\
\hline Paraphenylenediamine & 1 & 3.8 \\
\hline Fragrance mix & 4 & 15.5 \\
\hline Thiuram mix & 2 & 7.7 \\
\hline Black rubber mix & 1 & 3.8 \\
\hline
\end{tabular}

Patch test positive to two or more allergens was seen 5 of the 32 non atopic patients (15.6\%).

In both the groups, the most common sensitizer among women was nickel sulphate while the most common allergen among males was potassium dichromate.

\section{Discussion}

There is a slight male preponderance in the study group with male to female ratio 1.07:1. Indian studies by Handa et $\mathrm{al}^{2}(2: 1)$ and Laxmisha et $\mathrm{al}^{6}$ also showed a male predominance $(5: 1)$, while the studies done by Charan et $\mathrm{al}^{7}$ (1:1.09) and by Majid ${ }^{8}$ showed a female predominance (1:1.6). Interestingly, among the atopic patients in the study, there was a slight female predominance (1:1.2). The gender ratio varies greatly between studies and both men and women seems to be equally susceptible to the development of hand eczema.

Housewives comprised $28.6 \%$ of the study group followed by masons comprising $23.2 \%$. Housewives get exposed to a large number of chemicals, this along with impaired cutaneous barrier function in atopic individuals increases the 
risk of developing hand eczema. Housewives and masons constituted a large proportion in many studies $^{2,9}$. The work environment in high risk occupations like cleaning and construction is associated with a greater incidence of hand eczema.

Atopic diathesis is the most common endogenous cause of hand eczema. A personal history of atopy was present in $42.9 \%$ of our patients suggesting that it is an important predisposing factor for chronic hand dermatitis due to impaired cutaneous barrier function seen in atopic dermatitis. In our study, the percentage of atopic patients was similar to studies by Vigneshkarthik et $\mathrm{al}^{10}$ $(35.18 \%)$ and Suman et $\mathrm{al}^{9}$ (36\%), but surprisingly much higher than the study by Majid ${ }^{8}(0.04 \%)$ and the study done in Pondicherry ${ }^{6}$ where only a single patient out of 36 hand eczema patients had history of atopy. Dermatitis on the hands can be a manifestation of $\mathrm{AD}$, and it is therefore inherently problematic to associate the two disorders as they are part of the same syndrome ${ }^{11}$.

Pompholyx was seen in $14.3 \%$ (8 patients) in the present study similar to that seen in the study of Handa et $\mathrm{al}^{2}(14 \%)$. Out of our 8 patients, 4 gave a history of atopy. Though a significant correlation between pompholyx and atopy was noted in other studies $^{2,10}$, no significant association $(\mathrm{p}=0.659)$ could be found between the two in the present study. A study done in Denmark ${ }^{12}$ in 398 pompholyx patients also showed no association between the two.

Unspecified eczema accounted for $66.1 \%$ in our study which was in accordance with the study done by Handa et $\mathrm{al}^{2}(62 \%)$. This points out the fact that morphological classification of all patients of hand eczema is not always possible.

In our study, $70.8 \%$ of the atopics had a positive patch test. The positivity varies in different studies from $30 \%{ }^{11}$ to $55 \%{ }^{13}$.

The most common allergen among atopic individuals was thiuram mix $(22.3 \%)$ followed by potassium dichromate $(18.5 \%)$. Few studies ${ }^{2,11}$ found nickel sensitivity to be significantly more common in atopics, unlike in our study.
Potassium dichromate was the most common allergen among men, while nickel sulphate was the most common among women.

\section{Conclusions}

Hand eczema is a chronic distressing dermatological condition with significant physical, social and financial implications. Majority of the patients had a non specific morphology of hand eczema. A personal history of atopy was seen in $42.9 \%$. However, astatistically significant association between pompholyx and personal history of atopy could not be obtained. Thiuram mix followed by potassium dichromate were the most common allergens positive in atopic individuals. It is reasonable to recommend patch testing for atopic individuals in the same way as for non atopic individuals.

\section{References}

1. Berth-Jones J. Eczema, Lichenification, Prurigo and Erythroderma. In: Burns T, Breathnach S, Cox N, Griffiths C. editors. Rook's Textbook of Dermatology. 8th ed.Oxford: Wiley-Blackwell; 2010; p.23.1-23.51.

2. Handa S, Kaur I, Gupta T, Jindal R. Hand eczema: Correlation of morphologic patterns, atopy, contact sensitization and disease severity. Indian J Dermatol Venereol Leprol 2012;78:153-8.

3. Nilsson E, Mikaelsson B, Andersson S. Atopy, occupation and domestic work as risk factors for hand eczema in hospital workers. Contact Dermatitis 1985;13:21623.

4. Coenraads, PJ, Diepgen TL. Risk for hand eczema in employees with past or present atopic dermatitis. Int Arch Occup Environ Health 1998;71:7-13.

5. Rystedt I. Factors influencing the occurrence of hand eczema in adults with a history of atopic dermatitis in childhood. Contact Dermatitis 1985;12:185-91. 
6. Laxmisha C, Kumar S, Nath AK, Thappa DM. Patch testing in hand eczema at a tertiary care center. Indian J Dermatol Venereol Leprol 2008;74:498-9.

7. Charan UP, Peter CVD, Pulimood SA. Impact of hand eczema severity on quality of life. Indian Dermatol Online $\mathbf{J}$ 2013;4:102-5.

8. Majid I. Contact allergens causing hand eczema in ethnic Kashmiri population: A study of 7-years. Indian J Dermatol 2016;61:119.

9. Suman M, Reddy BS. Pattern of contact sensitivity in Indian patients with hand eczema. J Dermatol 2003;30:649-54.

10. VigneshkarthikN, Ganguly S, Kuruvila S. Patch Test as a Diagnostic Tool in Hand Eczema. J ClinDiagn Res 2016;10:WC04WC07.

11. Dotterud LK, Smith-Sivertsen T. Alleric contact sensitisation in the general adult population a population-based study from Northern Norway. Contact Dermatitis 2007; 56:10-15.

12. Bryld LE, Agner T, Menné T. Relation between vesicular eruptions on the hands and tinea pedis, atopic dermatitis and nickel allergy. Acta Derm Venereol 2003;83: 186-8.

13. Agner T, Andersen KE, Brandao FM, Bruynzeel DP, Bruze M, Frosch P, et al. Contact sensitisation in hand eczema patients-relation to subdiagnosis, severity and quality of life: A multi-centre study. Contact Dermatitis 2009;61:291-6. 